\title{
PRODUÇÃO DE IMUNORREAGENTES PARA USO EM UM TESTE IMUNOENZIMÁTICO DE DETECÇÃO DE SALMONELLA EM ALIMENTOS ${ }^{1}$
}

\author{
Regina Baptista dos REIS ${ }^{2, *}$, Elsa Masae MAMIZUKA ${ }^{3}$, Bernadette Dora Gombossy de Melo FRANCO ${ }^{4}$
}

\begin{abstract}
RESUMO
O objetivo deste trabalho foi o desenvolvimento de imunorreagentes policlonais convenientes para uso em um teste imunoenzimático para detecção rápida de Salmonella em alimentos. Foram produzidos seis anti-soros policlonais anti-Salmonella contendo as aglutininas e, h; 1,6; i; 1,2; f,g,s e m,t. Como antígenos, foram empregadas culturas formolizadas de quatro sorotipos de Salmonella (S. Typhimurium fases 1 e 2, $S$. Anatum fases 1 e 2 , $S$. Agona monofásica e $S$. Oranienburg monofásica) cultivadas em caldo tripticase de soja. O teste imunoenzimático utilizado foi o indireto, empregando-se anti-lgG-peroxidase como conjugado e OPD- $\mathrm{H}_{2} \mathrm{O}_{2}$ como sistema cromógeno. Os testes imunoenzimáticos foram conduzidos com os anti-soros policlonais individuais absorvidos e não-absorvidos, bem como empregandose um anti-soro polivalente, correspondente a um "pool" de antisoros absorvidos e não-absorvidos com culturas puras de Salmonella e outras enterobactérias. A absorção dos soros eliminou as reações cruzadas com todas as enterobactérias testadas nesse estudo, apresentadas tanto por alguns anti-soros individuais quanto pelo polivalente. Entre os seis anti-soros estudados, os que apresentaram melhor desempenho foram o f,g,s não-absorvido e o polivalente absorvido.
\end{abstract}

Palavras-chave: imunorreagentes; Salmonella; ensaio imunoenzimático.

\section{SUMMARY}

PRODUCTION OF IMMUNOREAGENTS TO BE USED IN A ENZYME IMMUNOASSAY FOR DETECTION OF SALMONELLA. This research aimed for the development of convenient policlonal immunoreagents to be used in an enzyme immunoassay for detection of Salmonella. Six anti-Salmonella antisera were prepared, which contained the following agglutinins: e, h. 1.6; i; 1.2 ; f,g,s and $m, t$. The antigens consisted of formolized cultures of four Salmonella serotypes ( $S$. Typhimurium phases 1 and $2, S$. Anatum phases 1 and $2, S$. Agona and $S$. Oranienburg), grown in tryptic soy broth. An indirect-type immunoassay was used, employing antiIgG-peroxidase as conjugate and OPD- $\mathrm{H}_{2} \mathrm{O}_{2}$ as chromogen. These tests were developed with individual and polivalent sera (pool of the individual sera), absorbed and non-absorbed with cultures of Salmonella and other enterobacteria. Absorption eliminated the cross reactions with enterobacteria, presented by some individual sera and by the polivalent serum. The best performance in the immunoassay was achieved by the non-absorbed f,g,s and by the absorbed polivalent sera.

\footnotetext{
${ }^{1}$ Recebido para publicação em 03/08/99. Aceito para publicação em 26/09/01.

2 Universidade Federal do Mato Grosso. Faculdade de Enfermagem e Nutrição - Departamento de Ciência, Tecnologia de Alimentos e Nutrição Básica. Av. Fernando Correia da Costa s $\mathbf{n}$. CEP 78068-900 - Cuiabá - MT - Brasil.

${ }^{3}$ Universidade de São Paulo. Faculdade de Ciências Farmacêuticas. Departamento de Análises Clínicas e Toxicológicas.

${ }^{4}$ Universidade de São Paulo. Faculdade de Ciências Farmacêuticas. Departamento de Alimentos e Nutrição Experimental.

${ }^{*}$ A quem a correspondência deve ser enviada.
}

Keywords: antibodies; Salmonella; enzyme immunoassay.

\section{1 - INTRODUÇÃO}

As salmonelas são amplamente distribuídas na natureza, sendo o trato-intestinal do homem e de animais o principal reservatório natural [1]. A presença desses patógenos em alimentos é um problema de saúde pública extremamente importante e não pode ser tolerada. Nos países em que há legislação pertinente à qualidade microbiológica dos alimentos, como o Brasil, elas devem estar ausentes em todos os tipos de alimentos, mas sua ocorrência tem sido bastante comum $[4,13,25]$.

As técnicas convencionais para detecção de Salmonella em alimentos envolvem um grande número de etapas e o tempo para obtenção de resultados é muito longo. Essas são as principais explicações para o surgimento de um número grande de novas técnicas para pesquisa de Salmonella em alimentos, entre as quais destacam-se as técnicas imunológicas, baseadas em reações antígeno-anticorpo [3, 12]. Entre as técnicas imunológicas, destacam-se as imunoenzimáticas que empregam anticorpos policlonais ou monoclonais marcados com uma enzima, normalmente cromogênica. Essa enzima funciona como um revelador da ocorrência da ligação do antígeno como o anticorpo específico, pois ao se adicionar ao sistema o substrato dessa enzima, há o desenvolvimento de cor.

Nos vários trabalhos conduzidos para investigar a possibilidade do emprego da técnica imunoenzimática para detectar Salmonella em alimentos, verificou-se que essa técnica, quando empregada em culturas puras ou aplicada em alimentos experimentalmente ou naturalmente contaminados, apresentou alta especificidade e/ou sensibilidade nos vários tipos de alimentos testados [10, 11].

A presente pesquisa foi elaborada objetivando a produção de imunorreagentes policlonais que se mostrassem convenientes para utilização em uma técnica imunoenzimática com potencial aplicação como teste de triagem para pesquisa de Salmonella em alimentos.

\section{2 - MATERIAIS E MÉTODOS}

\section{1 - Produção dos anti-soros}

Quatro cepas, doadas pelo Instituto Adolfo Lutz (IAL) de São Paulo, foram empregadas nesse estudo: $S$. Anatum fases 1 e 2, contendo as aglutininas e, h e 1,6, respectivamente, $S$. Typhimurium fases 1 e 2 contendo as aglutininas i e 1,2, respectivamente, $S$. Agona monofásica, com as aglutininas $f, g, s$ e $S$. Oranienburg 
monofásica, com as aglutininas $\mathrm{m}$,t. As cepas foram ativadas para a produção de flagelos por sete passagens sucessivas em meio semi-sólido MILi [32], com incubações a $37^{\circ} \mathrm{C}$ por 24 horas. Para a obtenção das culturas de $S$. Typhimurium e $S$. Anatum nas duas fases separadamente, utilizou-se o meio de fase reversa, conforme recomendado por EWING [8]. Em seguida, as cepas foram transferidas para $20 \mathrm{~mL}$ de caldo tripticase soja (TSB-Difco) e incubadas a $37^{\circ} \mathrm{C}$ por 24 horas. Posteriormente, as culturas foram tratadas com formol a $35 \%$ na concentração final de $0,5 \%$. Dessa forma, obtiveram-se seis suspensões de antígenos bacterianos monofásicos, contendo os aglutinogênios: e,h; 1,6; i; 1,$2 ; \mathrm{f}, \mathrm{g}, \mathrm{s}$ e m,t, que foram utilizados para a imunização de seis coelhos Nova Zelândia, machos, albinos, com 3 meses de idade, pesando $\pm 1,800 \mathrm{~kg}$. Os animais foram imunizados através da inoculação de uma das seis suspensões de antígenos bacterianos na veia marginal da orelha, injetando-se $0,2 \mathrm{~mL}$ no $1^{\circ}$ dia, $0,5 \mathrm{~mL}$ no $3^{\circ}$ dia, $1 \mathrm{~mL}$ no $7^{\circ}$ dia, e $2 \mathrm{~mL}$ nos $10^{\circ}, 24^{\circ}, 64^{\circ}$ e $80^{\circ}$ dias. A sangria final foi feita com 104 dias de imunização. A imunização dos animais foi realizada no biotério da Probac do Brasil Produtos Bacteriológicos Ltda. Os soros hiperimunes foram purificados utilizando-se sulfato de amônio a $40 \%$ [14] e posteriormente dialisados a $4{ }^{\circ} \mathrm{C}$ por 48 horas em solução salina tamponada com fosfato, $0,01 \mathrm{M}, \mathrm{pH} 7,5$ e concentrados em sacarose [5]. Em seguida, os soros foram absorvidos individualmente com cepas das enterobactérias: Proteus mirabilis, Providencia alcalifaciens, Citrobacter freundii, Escherichia coli, Enterobacter aerogenes e Serratia liquefaciens, conforme recomendado por EWING [8]. Após a absorção, os soros foram divididos em porções de $1 \mathrm{~mL}$ e estocados a $-20^{\circ} \mathrm{C}$. Posteriormente, preparou-se um soro polivalente, correspondente a um "pool" de anti-soros não-absorvidos e absorvidos, misturando-se $0,1 \mathrm{~mL}$ de cada um dos seis soros.

\section{2 - Microrganismos empregados como antígenos na padronização da técnica imunoenzimática}

As seguintes cepas de Salmonella, adquiridas na Seção de Coleção de Culturas do Instituto Adolfo Lutz (IAL), São Paulo, no Laboratório Fleury (LF), São Paulo e na Faculdade de Medicina Veterinária - USP (FMVZUSP), foram empregadas: $S$. Anatum (IAL, sem código), S. Typhimurium (IAL, sem código), S. Agona (IAL 642), S. Oranienburg (IAL 128), S. Montevideo (IAL 359/94), S. Havana (IAL 416/94), S. Newport (IAL 459/94), S. Give (IAL -K), S. Brandenburg (IAL, sem código), $S$. Bredeney (IAL12 - Fator 27), S. Panama (K IAL 1206 11/86), S. Cerro (IAL - soro), S. Infantis (IAL, sem código), S. Belem (LF), S. Inganda(LF), S. Stanleyville (LF), S. Dublin (LF), S. Derby (LF), S. Muenchen (LF), S. Saintpaul (LF), S. Ohio (LF), S. Madelia (LF), S. Gallinarum (FMVZ-USP). Foram também empregadas as seguintes cepas de enterobactérias: $S$. liquefaciens (IAL 1488 CDC 2126 9/86), P. alcalifaciens (IAL 9886 7/86), E. aerogenes (ATCC 4280), E. coli (IAL 1872), C. freundii (ATCC 8090) e $P$. mirabilis (IAL 1022).

\section{3 - Protocolo do teste imunoenzimático}

Utilizou-se um teste imunoenzimático do tipo nãocompetitivo. Como fase sólida para fixação dos antígenos, empregaram-se microplacas de poliestireno, com 96 cavidades de fundo chato (Costar, EUA). Para a padronização do teste imunoenzimático, seguiu-se a metodologia de CLARK, ENGVALL [6]. Duas cavidades (duplicatas) da microplaca foram sensibilizadas com $100 \mu \mathrm{L}$ de cada uma das culturas homólogas, correspondentes aos sorotipos de Salmonella utilizados na produção dos anti-soros, e heterólogas, correspondentes aos outros sorotipos de Salmonella empregados. Também foram utilizadas as culturas de S. liquefaciens, P. alcalifaciens, $E$. aerogenes, E. coli, C. freundii e $P$. mirabilis, diluídas em diferentes volumes de tampão carbonato/bicarbonato $0,05 \mathrm{M} \mathrm{pH} 9,6$, de forma a conter de $10^{2}$ a $10^{7} \mathrm{UFC} / \mathrm{mL}$. Como conjugado empregaram-se anti-IgG-peroxidase (Sigma Chemical Co, EUA) e OPH- $\mathrm{H}_{2} \mathrm{O}_{2}$ (Sigma Chemical Co, EUA) como sistema cromógeno. Para a leitura dos resultados, empregou-se um espectrofotômetro leitor de microplacas (Spectra, EUA) em comprimento de onda de $492 \mathrm{~nm}$.

A diferenciação entre resultados positivos e negativos foi feita através da determinação do valor "cut-off" [18], empregando-se a seguinte fórmula: cut-off $=\mathrm{mCN}$ $x 1,5$, onde $\mathrm{mCN}$ corresponde à média das leituras espectrofotométricas obtidas nos testes com as enterobactérias não pertencentes ao gênero Salmonella, testadas em todas concentrações mencionadas anteriormente (controles negativos).

\section{3 - RESULTADOS E DISCUSSÃO}

A Tabela 1 apresenta um resumo dos resultados encontrados nos testes imunoenzimáticos. A interpretação dos resultados seguiu o esquema proposto por KEMENY [18], ou seja, o resultado de um teste foi considerado negativo quando a densidade óptica determinada a $492 \mathrm{~nm}$ foi inferior a 1,5 vezes a média da densidade óptica determinada para os diversos controles negativos (mCN). Um resultado positivo "+" correspondeu àquele no qual a leitura espectrofotométrica foi maior ou igual a 1,5 vezes a $\mathrm{mCN}$ mas inferior a 5 vezes este valor. Por outro lado, o resultado positivo "++" correspondeu àquele em que a leitura espectrofotométrica estava entre 5 e 10 vezes o valor de $1,5 \times \mathrm{mCN}$. Testes nos quais a leitura espectrofotométrica foi superior a 10 vezes o valor de $1,5 \times \mathrm{mCN}$ foram considerados positivos "+++".

Entre os anti-soros individuais não-absorvidos, o anti-soro $f, g, s$ foi o mais sensível pois foi capaz de fornecer resultados positivos nas culturas contendo $10^{3} \mathrm{UFC} / \mathrm{mL}$, enquanto os anti-soros 1,$6 ; \mathrm{i} ; 1,2$ e $\mathrm{m}, \mathrm{t}$ foram capazes de detectar $10^{4} \mathrm{UFC} / \mathrm{mL}$. O anti-soro e,h não-absorvido foi capaz de detectar $10^{5} \mathrm{UFC} / \mathrm{mL}$. Em alguns casos, a sensibilidade melhorou quando os testes foram realizados com os anti-soros absorvidos: no caso do anti-soro e,h, sua sensibilidade passou de $10^{5} \mathrm{UFC} / \mathrm{mL}$ para $10^{4} \mathrm{UFC} / \mathrm{mL}$, e no caso dos anti-soros 
i e 1,2 , a sensibilidade aumentou de $10^{4} \mathrm{UFC} / \mathrm{mL}$ para $10^{2} \mathrm{UFC} / \mathrm{mL}$. O resultado da sensibilidade do anti-soro 1,6 não foi alterado pela absorção. Para os anti-soros $\mathrm{f}, \mathrm{g}, \mathrm{s}$ e $\mathrm{m}, \mathrm{t}$ o efeito da adsorção provocou diminuição em sua sensibilidade de $10^{3}$ para $10^{4} \mathrm{UFC} / \mathrm{mL}$ e de $10^{4}$ para $10^{5} \mathrm{UFC} / \mathrm{mL}$, respectivamente.

TABELA 1. Desempenho do teste imunoenzimático na detecção de Salmonella (homóloga e heteróloga) e de outras enterobactérias, empregando seis anti-soros monovalentes e um anti-soro polivalente

\begin{tabular}{|c|c|c|c|c|}
\hline & i-soros & $\begin{array}{l}\text { Reação com } \\
\text { Salmonella }\end{array}$ & $\begin{array}{l}\text { Reação com } \\
\text { Salmonella }\end{array}$ & $\begin{array}{c}\text { Reação com } \\
\text { enterobactérias n }\end{array}$ \\
\hline $\mathrm{e}, \mathrm{h}$ & não-absorvido & +++ & $+\mathrm{e}++$ & + \\
\hline & absorvido & ++ & + & - \\
\hline 1,6 & não-absorvido & +++ & + & + \\
\hline & absorvido & +++ & $-\mathrm{e}+$ & - \\
\hline $\mathrm{i}$ & não-absorvido & + & $-\mathrm{e}+$ & + \\
\hline & absorvido & + & $+\mathrm{e}++$ & - \\
\hline 1,2 & não-absorvido & + &,$+++\mathrm{e}+++$ & + \\
\hline & absorvido & + & $-\mathrm{e}++$ & - \\
\hline $\mathrm{f}, \mathrm{g}, \mathrm{s}$ & não-absorvido & +++ & $++\mathrm{e}+++$ & + \\
\hline & absorvido & +++ &,$-+\mathrm{e}++$ & - \\
\hline $\mathrm{m}, \mathrm{t}$ & não-absorvido & +++ & $+\mathrm{e}+++$ & + \\
\hline & absorvido & ++ &,$-+\mathrm{e}+++$ & - \\
\hline polivalente & não-absorvido &,$+++\mathrm{e}+++^{\mathrm{a}}$ &,$+++\mathrm{e}+++^{\mathrm{a}}$ & + \\
\hline & absorvido &,$+++\mathrm{e}+++^{\mathrm{a}}$ &,$+++\mathrm{e}+++^{\mathrm{a}}$ & - \\
\hline
\end{tabular}

a para todas as salmonelas testadas

Os anti-soros não-absorvidos apresentaram reações cruzadas com enterobactérias não pertencentes ao gênero Salmonella. Todos eles apresentaram reação positiva com a cepa de $C$. freundii utilizada, e alguns foram positivos também para as cepas de $E$. coli e $P$. alcalifaciens incluídas nos testes. Essas reações cruzadas foram completamente eliminadas pela absorção dos anti-soros.

Quanto à capacidade de reagir com as salmonelas, alguns anti-soros não reconheceram os sorotipos que continham os mesmos antígenos (somáticos e/ou flagelares). Assim, o anti-soro 1,6 absorvido não foi capaz de reagir com várias salmonelas testadas, entre elas S. Ohio, S. Brandenburg, S. Panama e S. Inganda. Mesmo a reação com outras salmonelas foi bastante fraca, o que já havia sido observado com o anti-soro 1,6 não-absorvido. O anti-soro i não-absorvido também não reagiu com todas as salmonelas utilizadas neste estudo: a reação com $S$. Infantis foi negativa em todas as concentrações testadas. No entanto, quando este anti-soro foi absorvido, a reação com $S$. Infantis foi positiva somente quando esta se encontrava com $10^{7} \mathrm{UFC} / \mathrm{mL}$. Os anti-soros 1,2 e f,g,s absorvidos, não foram capazes de reagir com $S$. Gallinarum, assim como o antisoro $m$,t absorvido, não reagiu com $S$. Cerro e $S$. Ohio. Alguns anti-soros apresentaram reação positiva com salmonelas que apresentavam antígenos comuns quando estas estavam em concentração muito elevada. Um exemplo disto é o que ocorreu com os anti-soros e,h e 1,6 absorvidos que só reagiram com $S$. Belem, $S$. Newport e $S$. Bredeney, quando estas estavam presentes na concentração de $10^{7} \mathrm{UFC} / \mathrm{mL}$.

O soro polivalente não-absorvido e o "pool" de antisoros absorvidos detectaram todos os sorotipos de
Salmonella testados, apresentando ambos sensibilidade de $10^{3} \mathrm{UFC} / \mathrm{mL}$. O soro polivalente não-absorvido revelou resultados falso-positivos com $C$. freundii, $P$. alcalifaciens e $P$. mirabilis, que foram eliminados com a absorção.

A sensibilidade dos anti-soros testados neste trabalho foi concordante com a observada em vários outros trabalhos realizados com diferentes técnicas imunoenzimáticas e sorotipos de Salmonella [15, 20, $21,26]$. Nestes estudos, a sensibilidade do teste imunoenzimático variou de $10^{2}$ a $10^{6} \mathrm{UFC} / \mathrm{mL}$.

As reações cruzadas com as enterobactérias obtidas por ocasião do estudo com os anti-soros não-absorvidos podem ser explicadas pelas estreitas relações antigênicas somáticas entre Salmonella e outras enterobactérias e que já haviam sido descritas por KAUFFMANN [17] e ØRSKOV, ØRSKOV [23]. Reações falso-positivas também foram verificadas em diferentes testes imunoenzimáticos ou de imunodifusão. KRYSINSKI, HEIMSCH [19] verificaram que um soro comercial anti-H para Salmonella, utilizado para fins de identificação sorológica e empregado em um teste imunoenzimático indireto idealizado pelo autores, revelouse inespecífico, ocorrendo reações cruzadas com $C$. freundii, E. coli, E. aerogenes, P. fluorescens, Erwinia sp. e Proteus sp. OLIVEIRA et al. [22], trabalhando com anticorpos policlonais para detecção de $S$. Enteritidis em alimentos, verificaram que o anti-soro apresentou reações cruzadas com $C$. freundii, Proteus mirabilis e Morganella morganii. SANTOS, ALEIXO [27], testando um ELISA indireto com soro polivalente somático antiSalmonella, verificaram reações fracamente cruzadas com uma cepa de $P$. mirabilis e uma de $C$. freundii.

BARBER, EYLAN [2], avaliando soros policlonais para vários sorotipos de Salmonella, através do teste de imunodifusão em gel com antígenos homólogo e heterólogo, bem como com antígenos de Shigella sonnei e E. coli, verificaram que esses soros apresentaram reação cruzada com antígenos heterólogos de Salmonella, e também de outros membros da família Enterobacteriaceae.

D'AOUST, SEWELL [7], avaliando a sensibilidade e a especificidade do teste imunoenzimático comercial Bio-Enzabead (pérolas adsorvidas com anticorpo monoclonal polivalente da classe $\lg A$ ), relataram que 5 das 77 cepas de enterobactérias testadas deram reações falso-positivas. Entre elas, quatro eram $C$. freundi e uma era $M$. morganii.

É importante, no entanto, ressaltar que vários autores reportaram ausência de resultados falso-positivos com enterobactérias [9, 16, 20, 26, 31, 33].

Reações falso-negativas também eram esperadas, visto que várias já haviam sido relatadas na detecção de Salmonella em testes imunoenzimáticos. SMITH, JONES [31], ROBISON, PRETZMAN, MATTINGLY [26]; MATTINGLY, GEHLE [20] verificaram que o anticorpo monoclonal M 467 não reagiu com os sorotipos tifóide e paratifóide (S. Typhi, S. Paratyphi A e S. Paratyphi 
B). Esse mesmo anticorpo não reagiu também com outros sorotipos, incluindo S. Kirkee [25], S. Tennessee e S. Newington [20, 26] e S. Potsdan [20].

D'AOUST, SEWELL [7] encontraram resultados falsonegativos com cepas de $S$. Hvittingfoss, utilizando o teste imunoenzimático comercial Bio-Enzabead, concluindo que estas reações poderiam estar relacionadas à ausência de determinantes antigênicos comuns nesta sorovariedade.

Cabe ressaltar que as reações falso-negativas para Salmonella em testes imunoenzimáticos podem estar relacionadas às condições de revestimento que foram usadas para a adsorção dos antígenos às microplacas, que não permaneceram aderidos durante os procedimentos de lavagens [19]. A avidez de ligação entre os antígenos e os soros testados pode ter também um papel importante nessas reações [29].

As reações cruzadas apresentadas pelos anti-soros testados nesse trabalho com diferentes sorotipos de Salmonella estão baseadas nas fortes relações antigênicas existentes entre estes sorotipos, conforme relatado por vários pesquisadores [24, 28, 30].

Com base nos resultados obtidos, pode-se concluir que o desempenho do anti-soro policlonal f,g,s nãoabsorvido e do "pool" de anti-soros absorvidos para a detecção de Salmonella através de um teste imunoenzimático é bastante promissor. Sua conveniência para detecção de Salmonella em alimentos depende ainda de testes com alimentos experimentalmente e naturalmente contaminados.

\section{4 - CONCLUSÕES}

Para utilização em testes imunoenzimáticos para detecção rápida de Salmonella, dois anti-soros policlonais testados podem ser recomendados: o absorvido polivalante e o monovalente não-absorvido, contendo as aglutinas $\mathrm{f}, \mathrm{g}, \mathrm{s}$. Este estudo mostrou que estes anti-soros, foram os mais sensíveis, sendo capazes de detectar Salmonella em culturas contendo apenas $10^{3} \mathrm{UFC} / \mathrm{mL}$, independentemente do sorotipo da Salmonella. O anti-soro f,g,s não-absorvido apresentou algumas reações cruzadas com outras enterobactérias, o que não ocorreu com o soro polivalente absorvido.

\section{5 - REFERÊNCIAS BIBLIOGRÁFICAS}

[1] ANDERSON, J.M.; HARTMAN, P.A. Direct immunoassay for detection of Salmonellae in foods and feeds. Appl. Environ. Microbiol., v. 49, n. 5, p. 1124-1127, 1985.

[2] BARBER, C.; EYLAN, E. The numerous common antigens of Enterobacteriaceae. Zbl. Bakt. Hyg. Abt. I Orig. A, v. 244, p. 251-259, 1979.

[3] BLACKBURN, C. de W. Rapid and alternative methods for detection of salmonellas in foods. J. Appl. Bacteriol., v. 75, p. 199-214, 1993.

[4] CALDERON, D..F.; FURLANETTO, S.M.P. Isolamento de Salmonella em diferentes meios seletivos de enriquecimento, tempos e temperaturas de incubação. Rev. Microbiol., v. 22, p. 127-130, 1991.
[5] CAMPBELL, D.H.; GARVEY, F.S.; CREMER, N.E.; SUSSDORF, D.H. Methods in immunology. 2.ed. Massachusetts: Benjamin. 1970, 454p.

[6] CLARK, B.R.; ENGVALL, E. Enzyme-linked immunosorbent assay (ELISA): Theoretical and practical aspects. In: MAGGIO, E.T. Enzyme Immunoassay. Florida:CRC Press, 1981.295p. p. 167-180.

[7] D'AOUST, J.-Y.; SEWELL, A.M. Detection of Salmonella by the enzyme immunoassay (EIA) technique. J. Food Sci., v. 51, n. 2, p. 484-488, 507, 1986.

[8] EWING, W.H. Identification of Enterobacteriaceae. 4. th. New York: Elsevier Science Publishing, 1986. 563p.

[9] EMSWILER-ROSE, B.; GEHLE, W.D.; JOHNSTON, R.W.; OKREND, A.; MORAN, A.; BENNETT, B. An enzyme immunoassay technique for detection of Salmonellae in meat and poultry products. J. Food Sci., v. 49, n. 4, p. 10181020, 1984.

[10] FELDSINE, P.T.; FALBO-NELSON, M.T.; HUSTEAD, D.L. Polyclonal enzyme immunoassay method for detection of motile and non-motile Salmonella in foods: Collaborative study. J. Assoc. Off. Anal. Chem. Int., v. 75, n. 6, p. 1032-1044, 1992.

[11] FELDSINE, P.T.; FALBO-NELSON, M.T.; HUSTEAD, D.L. Polyclonal enzyme immunoassay method for detection of motile and non-motile Salmonella in foods: Collaborative study. J. Assoc. Off. Anal. Chem. Int., v. 76, n. 3, p. 694697, 1993.

[12] FRANCO, B.D.G.M.. Métodos alternativos de análise microbiológica: uma revisão. Bol. SBCTA, v. 33, n. 2, p. 2292234, 1999.

[13] FUZIHARA, T.O.; FRANCO, B.D.G.M. Bactérias patogênicas e bactérias indicadoras de higiene em carne suína comercializada em Santo André - S.P. Ciênc. Tecnol. Aliment., v. 13, n. 1, p. 77-88, 1993.

[14] GARDEY, J.S.; CREMER, N.E.; SUSSDORF, D.H. Ammonium sulfate precipitation. In: CAMPBELL, D.H. Methods in immunology, Massachusetts: Benjamin, 1977. p. 218219.

[15] IBRAHIM, G.F.; FLEET, G.H.; LYONS, M.J.; WALKER, R.A. Immunological relationships between Salmonella flagella and their potential application for salmonellae detection by immunoassay. Med. Microbiol. Immunol., v. 174, n. 2 , p. 87-99, 1985.

[16] JARADAT, Z.E; ZAWISTOWSKI, J. Production and characterization of monoclonal antibodies against the O5 antigen of Salmonella typhimurium lipopolysaccharide. Appl. Environ. Microbiol., v. 62, n. 1, p. 1-5, 1996.

[17] KAUFFMANN, F. The bacteriology of Enterobacteriaceae. Munksgaard-Copenhagen: Scandinavian University Books, 1966. 400p.

[18] KEMENY, D.M. A practical guide to ELISA. New York: Pergamon Press, 1991. 115p.

[19] KRYSINSKI, E.P.; HEIMSCH, R.C. Use of enzyme-labeled antibodies to detect Salmonella in foods. Appl. Environ. Microbiol., v. 33, n. 4, p. 947-954, 1977.

[20] MATTINGLY, J.A.; GEHLE, W.D. An improved enzyme immunoassay for the detection of Salmonella. J. Food Sci., v. 49, n. 3, p. 807-809, 1984.

[21] MINNICH, S.A.; HARTMAN, P.A.; HEIMSCH, R.C. Enzyme immunoassay for detection of Salmonellae in foods. Appl. Environ. Microbiol., v. 43, n. 4, p. 877-883, 1982.

[22] OLIVEIRA, K.M.P.; NAKANO, M.H.; HERRERO, H.; HIROOKA, E.Y.; OLIVEIRA, T.C.R.M. Produção de anticorpos 
policlonais para Salmonella enteritidis. In: XIX CONGRESSO BRASILEIRO DE MICROBIOLOGIA, Rio de Janeiro, RJ, .11-15 de novembro de 1997.

[23] ØRSKOV, F.; ØRSKOV, I. Serotyping of Enterobacteriaceae, with special emphasis on $\mathrm{K}$ antigen determination. In: BERGAN, T. Methods in Microbiology. London: Academic Press, v. 14, 1984. Cap. 2. p. 43-111.

[24] PARISH, C.R. Immune response to chemically modified flagelin. II. Evidence for a fundamental relationship between humoral and cell-mediated immunity. J. Exp. Med., v. 134, p. 2147, 1971.

[25] REIS, R.B.; KRUGER, C.S.; MACIEL, M.S. Salmonella spp. em produtos cárneos comercializados no município de Cuiabá-MT. Avaliação da metodologia de pesquisa. Modelos de resistência a drogas antimicrobianas. Ciênc. Tecnol. Aliment., v. 15, n. 1, p. 74-78, 1995.

[26] ROBISON, B.J.; PRETZMAN, C.I.; MATTINGLY, J.A. Enzyme immunoassay in which a myeloma protein is used for detection of Salmonellae. Appl. Environ. Microbiol., v. 45, n. 6, p. 1816-1821, 1983.

[27] SANTOS, A.; ALEIXO, J.A.G. Um ELISA indireto para detecção de salmonelas em alimentos. In: XIX CONGRESSO BRASILEIRO DE MICROBIOLOGIA, Rio de Janeiro, RJ, 1115 de novembro de 1997.
[28] SCHUURS, A.H.W.M.; van WEEMEN, B.K. Enzymeimmunoassay. Clin. Chem., v. 81, n. 1, p. 1-40, 1977.

[29] SMITH, A.M.; POTTER, M. A BALB/c mouse IgA myeloma protein that binds Salmonella flagellar protein. J. Imunol., v. 114, n. 6, p. 1847-1850, 1975.

[30] SMITH, A.M.; MILLER, J.S.; WHITEHEAD, D.S. M467: a murine IgA myeloma protein tha binds a bacterial protein. J. Immunol., v. 123, n. 4, p. 1715-1720, 1979.

[31] SMITH, A.M.; JONES, C. Use of murine myeloma protein M467 for detecting Salmonella spp. in milk. Appl. Environ. Microbiol., v. 46, n. 4, p. 826-831, 1983.

[32] TOLEDO, M.R.F.; FONTES, C.F.; TRABULSI, L.R. MILi um meio para a realização dos testes de motilidade, indol e lisina descarboxilase. Rev. Microbiol., v. 13, n. 3, p. 230-235, 1982

[33] TSANG, R.S.W.; NIELSEN, K.H.; JOHNSON, W.M. Development of an indirect whole cell ELISA for the rapid identification of Salmonella. J. Rapid Meth. Autom. Microbiol., v. 4, p. 139-154, 1995.

\section{6 - AGRADECIMENTOS}

À Probac do Brasil - Produtos Bacteriológicos Ltda, pelo apoio, doação dos animais e concessão de seu biotério para a imunização dos animais. 